\title{
Performa Mekanik Beton Berpori Untuk Aplikasi Perkerasan
}

\author{
Agus Kurniawan ${ }^{1, *}$, Dadang Ardi Pranata ${ }^{2}$ \\ Departemen Teknik Sipil, Universitas Gadjah Mada, Yogyakarta ${ }^{1}$, DTS Sekolah Vokasi, Universitas Gadjah Mada, Yogyakarta ${ }^{2}$ \\ Koresponden*, Email: aguskurniawan@ugm.ac.id
}

\begin{tabular}{lr}
\hline & Info Artikel \\
\hline Diajukan & 31 Desember 2018 \\
Diperbaiki & 24 September 2019 \\
Disetujui & 25 September 2019
\end{tabular}

\begin{abstract}
The application of pavement using conventional type has a lot of undesirable effects on the availability of soil water that covers and prevents infiltration water to soil. Therefore, it would require a better option for the construction of pavements using pervious concrete which allowing water penetration to soil. Infiltration, compressive strength and flexural strength tests were used in this experiment. Six samples were used with variations of void $5 \%, 10 \%$, $15 \%, 20 \%, 25 \%, 30 \%$ and cement substitution with silica fume of $10 \%$ the weight of cement. The largest infiltration capability was achieved by $30 \%$ porous void concrete with falling head values of $10.49 \mathrm{~cm} / \mathrm{s}$ and the smallest $1.1 \mathrm{~cm} / \mathrm{s}$ at $5 \%$ void. The result of compressive strength showed that the strongest data was found in void 5\% at $15.45 \mathrm{MPa}$ and the weakest was void $30 \%$ with $3.45 \mathrm{MPa}$. The results of flexural strength depicted that the strongest data found in $10 \%$ void with $2.26 \mathrm{MPa}$ and the weakest in $30 \%$ void with $0.49 \mathrm{MPa}$.
\end{abstract}

conservation, pavement, environmentally friendly

\begin{abstract}
Abstrak
Penggunaan perkerasan jalan dengan menggunakan tipe konvensional banyak menimbulkan dampak yang tidak kita inginkan pada ketersediaan air dalam tanah, karena menutupi dan menghalangi air masuk kedalam tanah. Maka diperlukan pilihan yang lebih baik untuk pembangunan perkerasan yang ramah terhadap lingkungan menggunakan beton berpori yang mampu memasukkan air ke dalam tanah. Uji yang digunakan adalah infiltrasi, kuat tekan, dan kuat lentur. Pada penelitian ini digunakan 6 sampel dengan variasi void $5 \%, 10 \%, 15 \%, 20 \%, 25 \%, 30 \%$ dan subtitusi semen memakai silica fume dengan $10 \%$ dari berat semen. Kemampuan infiltrasi terbesar dicapai beton berpori $30 \%$ void dengan nilai falling head sebesar $10,49 \mathrm{~cm} / \mathrm{s}$ dan terkecil $1,1 \mathrm{~cm} / \mathrm{s}$ pada void 5\%. Hasil dari kuat tekan terbesar pada void 5\% di angka 15,45 MPa dan yang terlemah di void $30 \%$ dengan 3,45 MPa. Hasil dari kuat lentur yang terkuat terdapat pada void $10 \%$ dengan hasil 2,26 MPa dan yang paling kuat dengan void $30 \%$ dengan 0,49 MPa.
\end{abstract}

Kata kunci: beton berpori, konservasi air, perkerasan, ramah lingkungan yang diinginkan. Beton berpori sendiri tersusun dari campuran beton tanpa pasir dan mortar dengan proporsi dan desain yang ditentukan sesuai dengan penggunaan. Pembuatan beton berpori dalam pengerjaannya secara umum sama dengan beton konvensional yang dalam pelaksanaannya dapat dibuat dengan mudah dan paktis. Meskipun dalam beberapa hal pembuatan beton berpori juga bisa dilakukan dengan penambahan foam agent [1].

Beton berpori cenderung memiliki nilai slump yang mendekati nol atau zero slump, sehingga menurunkan tingkat workability beton, untuk itu diperlukan bahan tambah lain untuk meningkatkan kelecakan sekaligus kekuatan yaitu silica fume. Kombinasi beberapa material tersebut akan menghasilkan material yang mengeras dan mampu meloloskan air dengan baik sesuai desain [2].

Bahan silica fume sebagai bahan tambah dalam campuran beton mampu menghasilkan beton dengan kuat tekan yang lebih besar dari beton normal. Beton dengan silica fume dapat mengurangi pori di pasta semennya, karena bahan tambah kan. Penelitian ini berfokus pada beton berpori, yang berarti 
(additive) ini bersifat mineral yang lebih banyak bersifat cementitious dan banyak digunakan untuk memperbaiki kinerja kekuatan beton. Silica fume merupakan material pozollan yang sangat halus, dan juga mempunyai kadar kandungan senyawa $\mathrm{SiO}_{2}$ yang sangat tinggi yaitu lebih besar dari $90 \%$ serta berukuran sekitar 1/100 ukuran rata-rata partikel semen. Material silica fume jika dihasilkan dari tanur tinggi atau sisa produksi silikon atau alloy besi silikon mempunyai kandungan silika yang lebih banyak. Pemakaian silica fume dengan proporsi $0-30 \%$ mampu meningkatkan karakteristik kekuatan beton dengan faktor air semen sebesar 0,34 dan 0,28. Performa beton umumnya akan lebih baik jika menggunakan superplastisizer sehingga kuat tekan dan kelecakan akan lebih baik [3].

Aplikasi silica fume juga dapat mengurangi penggunaan air pada bahan beton dan adanya bahan ini mampu mengisi pori-pori di beton serta membentuk reaksi pozzolan yang meningkatkan kuat beton, sehingga menjadikan beton menjadi kedap, awet, dan berkekuatan tinggi. Bahan utama beton terdiri dari agregat yang bisa dianggap sebagai frame dan pasta semen adalah matriks pengisi. Analogi ini juga membagi pasta semen menjadi dua daerah yaitu daerah tengah dan daerah transisi yang berupa batas antara agregat dengan pasta. Daerah tengah umumnya mempunyai kekuatan yang cukup, tetapi pada daerah transisi ada potensi bleeding sehingga terjadi kelemahan di daerah ini dibanding dengan daerah tengah. Silica fume berfungsi memadatkan daerah transisi, sehingga rekatan antara pasta dari semen dan agregat batuan bisa lebih kompak. Agregat serta pasta mampu menyatu membentuk struktur komposit yang lebih solid dan kuat [4]. Selain itu penambahan silica fume juga mampu menambah kelecakan beton sehingga akan mempermudah dalam pelaksanaan pengecoran beton berpori karena memang beton jenis ini biasanya cenderung lebih sulit dikerjakan mengingat nilai slump yang rendah.

\section{Keunggulan dan pengaplikasian}

Keunggulan utama beton berpori adalah kemampuanya dalam meloloskan air dengan volume yang relatif besar melalui struktur pori yang terhubung pada luasan permukaan beton, maka pengisian air tanah dapat dilakukan dengan baik [4]. Beton berpori mampu meningkatkan ketahanan roda kendaraan terhadap selip melalui pengurangan jumlah air dipermukaan jalan, sehingga keamanan dalam berkendara maupun berjalan di perkerasan yang menggunakan beton berpori lebih baik dan juga dengan adanya skid resistance akan memudahkan roda menempel pada perkerasan. Kemampuan lain dari beton berpori adalah bahan ini bisa memantulkan sinar ultraviolet yang berasal dari sinar matahari, sehingga memungkinkan menyerap lebih sedikit panas dibandingkan dengan aspal. Dibandingkan dengan beton normal, beton berpori juga mampu menyimpan panas matahari lebih sedikit daripada beton normal. Dengan demikian, beton berpori dapat diaplikasikan dengan baik di daerah dengan suhu yang tinggi $[5,6]$.

\section{Metode}

\section{Infiltrasi/Falling Head}

Dalam menentukan konduktivitas hidrolik sistem beton berpori sebagian besar penelitian menggunakan alat fallinghead yang diadaptasi dari pengujian tanah. Meskipun metode lain juga telah digunakan untuk mengukur konduktifitas hidrolik beton berpori baik di laboratorium maupun lapangan, akan tetapi uji ini menghasilkan angka yang lebih teliti dalam menentukan kemampuan beton meneruskan air ke dalam tanah dalam aplikasi perkerasan. Uji infiltrasi dilakukan dengan maksud meneliti seberapa cepat beton berpori dalam meloloskan air. Uji infiltrasi dilakukan seperti tergambar dalam Gambar 1.



Gambar 1. Uji Infiltrasi

Dalam uji ini, sampel akan dikurung dalam cetakan dan dilapisi dengan lembaran karet tipis dan dikencangkan dengan klem selang untuk meminimalkan aliran di sepanjang sisi cetakan yang akan mempengaruhi pengukuran konduktivitas hidrolik. Sampel kemudian dihubungkan ke PVC vertikal sisi hulu dan hilir, setelah itu diukur waktu yang diperlukan air untuk sepenuhnya melewati beton berpori sehingga sama level antara hulu dan hilir, yang kemudian nilai infiltrasi dapat dihitung berdasarkan waktu ini. Secara 
teoritis, formula untuk menghitung infiltrasi diambil dari modifikasi ASTM C1701 dengan rumus sebagai berikut:

$$
\begin{aligned}
I=\frac{4 V}{D^{2} \pi t} & \\
\text { dengan } I & =\text { Infiltration }(\mathrm{cm} / \mathrm{s}) \\
\mathrm{V} & =\text { Volume air }\left(\mathrm{cm}^{3}\right) \\
\mathrm{D} & =\text { Diameter specimen }(\mathrm{cm}) \\
\mathrm{t} & =\text { Waktu air surut }(\mathrm{s})
\end{aligned}
$$

\section{Sensor Accelerometer}

Accelerometer merupakan sensor yang mempunyai fungsi untuk mengukur percepatan. Alat ini juga mampu mendeteksi dan mengukur getaran, mengukur defleksi akibat beban dinamis, serta kecepatan pada benda yang diukur baik dengan melibatkan pengaruh gravitasi atau tidak. Hasil bacaan pada alat ini berupa tegangan keluaran berbanding dengan percepatan gravitasi $(\mathrm{mV} / \mathrm{g})$ yang menunjukkan percepatan dari sampel yang dilekati sensor accelerometer tersebut. Setting alat pada sampel ditunjukkan pada Gambar $\mathbf{2}$, dengan jumlah sensor dua buah pada tengah bentang dan semperempat bentang.

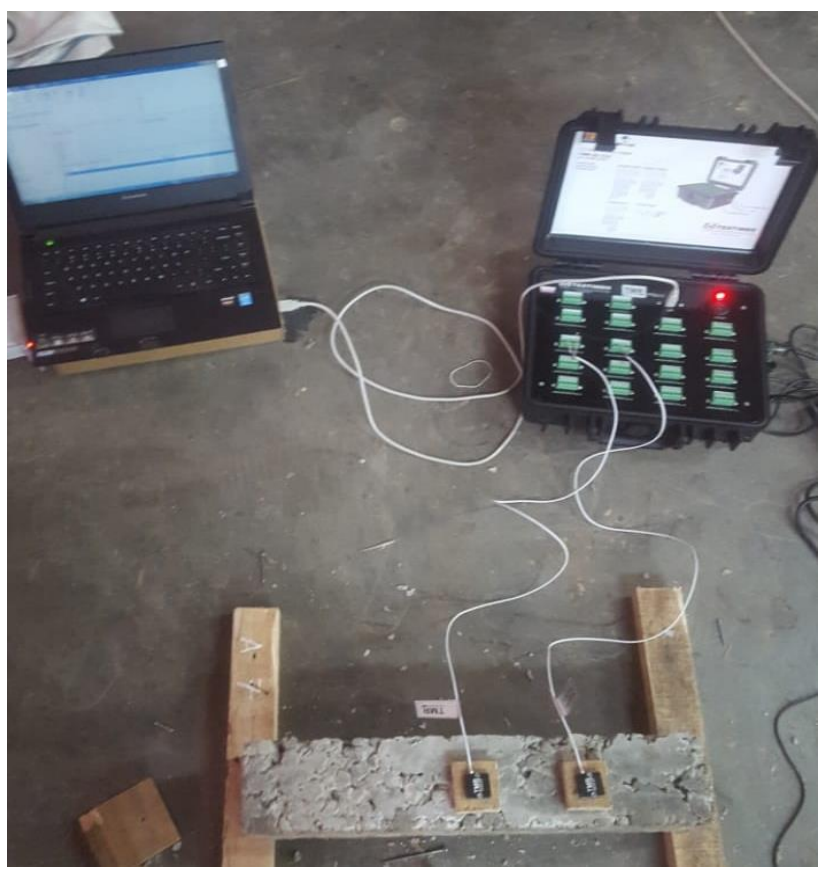

Gambar 2. Sensor accelerometer

\section{Natural Frequency terhadap Nilai Kekakuan Beton}

Pengukuran percepatan yang tercatat pada accelerometer digambarkan dengan diagram percepatan dan waktu. Diagram ini dianalisa menggunakan metode Fast Fourier Transform untuk menghasilkan natural frequency (waktu getar alami). Nilai kekakuan (stiffness) pada sampel dapat dianalisa mengingat terdapat hubungan antara waktu getar alami dengan nilai kekakuan pada beton. Hubungan tersebut dijabarkan dengan formula:

$F_{n}=\frac{1}{2 \pi} \sqrt{\frac{k}{m}}$

dengan $k$ adalah kekakuan, $F_{n}$ adalah natural frequency, dan $m$ adalah masa beton berpori.

\section{Proporsi Beton Berpori.}

Proses perhitungan proporsi bahan beton berpori, menggunakan acuan standar NRMCA (National Ready Mix Concrete Association) dengan desain void 5\%, 10\%, 15\%, $20 \%, 25 \%, 30 \%$ [7]. Pembuatan beton dilakukan dengan mencampur $10 \%$ silica fume dari berat semen sebagai bahan tambah beton. Desain campuran beton menggunakan perbandingan rasio semen dan air sebesar 0,3 dan menggunakan agregat kasar dengan ukuran 19-9,5 mm. Secara keseluruhan proporsi bisa dilihat dengan Tabel 1.

Tabel 1. Proporsi bahan beton berpori

\begin{tabular}{ccccc}
\hline $\begin{array}{c}\text { Void } \\
\text { Beton }\end{array}$ & $\begin{array}{c}\text { Semen } \\
(\mathrm{kg})\end{array}$ & $\begin{array}{c}\text { Air } \\
(\mathrm{kg})\end{array}$ & $\begin{array}{c}\text { Kerikil } \\
\text { SSD } \\
(\mathrm{kg})\end{array}$ & $\begin{array}{c}\text { Silica } \\
\text { Fume } \\
(\mathrm{kg})\end{array}$ \\
\hline $5 \%$ & 825,59 & 247,67 & 1165,47 & 82,55 \\
$10 \%$ & 744,65 & 223,39 & 1165,47 & 74,46 \\
$15 \%$ & 663,71 & 199,11 & 1165,47 & 66,63 \\
$20 \%$ & 582,77 & 174,83 & 1165,47 & 58,27 \\
$25 \%$ & 501,83 & 150,54 & 1165,47 & 50,18 \\
$30 \%$ & 420,89 & 126,26 & 1165,47 & 42,08 \\
\hline
\end{tabular}

\section{Hasil dan Pembahasan \\ Kuat Tekan Beton}

Hasil kuat tekan beton pada umur 28 hari pada variasi void 5\% yang merupakan beton dengan variasi void terkecil pada percobaan ini mempunyai kuat tekan yang paling besar. Uji kuat tekan pada beton dengan void 5\% yang terbesar adalah 15,45 MPa dan terkecil adalah 14,5 MPa Sedangkan pada variasi void $10 \%$ kuat tekan yang terbesar adalah 12,4 $\mathrm{MPa}$ dan terkecil adalah 11,7 $\mathrm{MPa}$. Variasi void $15 \%$ menunjukkan tekstur void yang terlihat lebih besar dibandingkan beton dengan variasi void $10 \%$. Pada variasi ini kuat tekan yang terbesar adalah $11,1 \mathrm{MPa}$ dan terkecil adalah 10,3 MPa. Pada uji kuat tekan beton variasi $20 \%$ yang terbesar adalah 8,3 $\mathrm{MPa}$ dan terkecil adalah 7,6 $\mathrm{MPa}$. Sedangkan variasi void $25 \%$ menunjukkan kuat tekan beton terbesar 4,6 MPa dan terkecil 3,7 MPa. Variasi void 30\% yang merupakan beton dengan tekstur void lebih besar dibanding variasi lain, sehingga kuat tekan yang didapat juga 
lebih kecil, pada uji kuat tekan beton variasi $30 \%$ didapatkan kuat tekan terbesar 4,2 MPa dan terkecil adalah 3,45 MPa. Sebaran nilai kuat tekan berada di rentang antara 3,45 $\mathrm{MPa}$ dan terbesar di angka 15,45 MPa yang hal ini sejalan dengan berbagai penelitian lainnya yang nilai tersebut berkisar antara $5 \mathrm{MPa}$ sampai $35 \mathrm{MPa}[8,9,10]$.

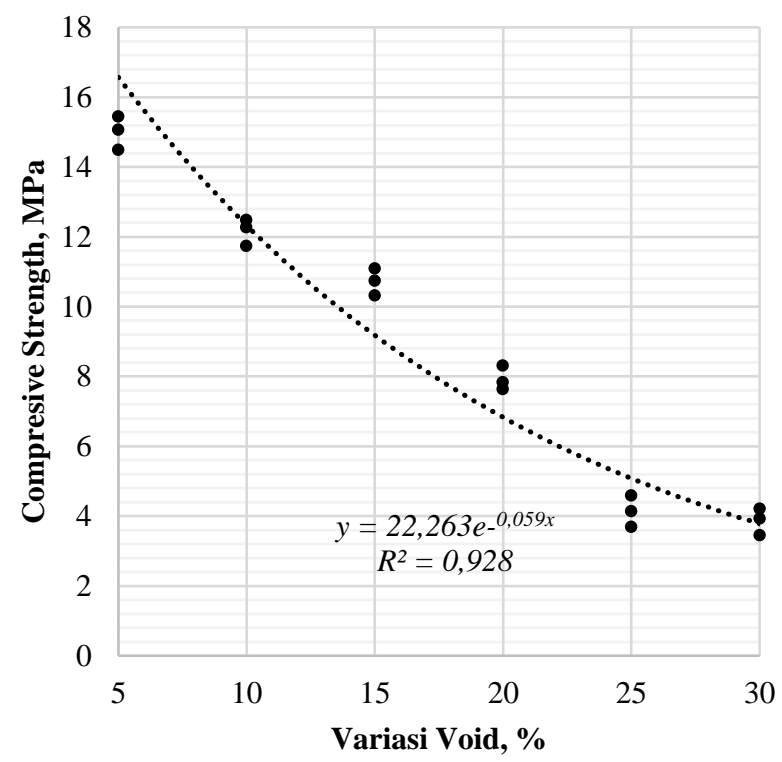

Gambar 3. Hubungan Void dan Kuat Tekan Beton Berpori Sumber: Hasil Analisis

Gambar 3 menunjukkan bahwa semakin kecil void akan menambah kuat tekan pada beton berpori, dan apabila semakin lebar void akan mempengaruhi kecilnya kuat tekan pada beton. Void yang lebih kecil akan memperbanyak elemen pasta pada beton sehingga kuat tekan akan semakin besar yang hal ini sejalan dengan penelitian oleh Meininger [11]. Sedangkan untuk pengaplikasian perkerasan jalan raya Meininger mensyaratkan void minimum sebesar $15 \%$.

\section{Hasil Pengujian Kuat Lentur Beton}

Hasil pengujian kuat lentur beton berpori dapat ditunjukkan pada Gambar 4 yang memperlihatkan adanya hubungan yang saling mempengaruhi antara kuat lentur beton dan variasi void pada beton berpori. Semakin kecil void pada beton berpori maka akan semakin besar pula kuat lentur pada beton berpori, karena semakin lebar void beton berpori akan mempengaruhi kekakuan lentur dengan semakin kecilnya kuat lentur pada beton.

Hubungan antara void dan kuat lentur dapat diregresikan dengan hubungan $y=2,2876 e^{-0,039 x}$ dengan nilai $R^{2}=0,688$. Hubungan antarta kuat void dan kuat lentur ini dapat menjadi dasar perencanaan beton berpori pada aplikasi di lapangan.

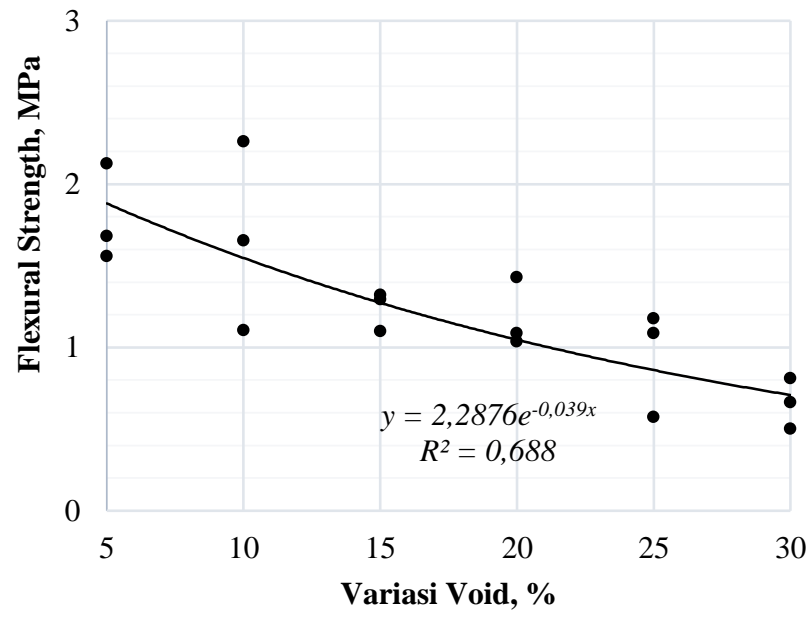

Gambar 4. Hubungan Void dan Kuat Lentur Beton Berpori Sumber: Hasil Analisis

Secara menyeluruh pengujian kuat lentur menunjukkan bahwa hasil terbesar didapat pada beton void $10 \%$ dengan nilai 2,26 MPa dan terkecil adalah 0,49 MPa pada void 30\%. Hasil ini hampir sama dengan beberapa hasil penelitian yang berkisar 0,1 MPa sampai $5 \mathrm{MPa}[12,13]$.

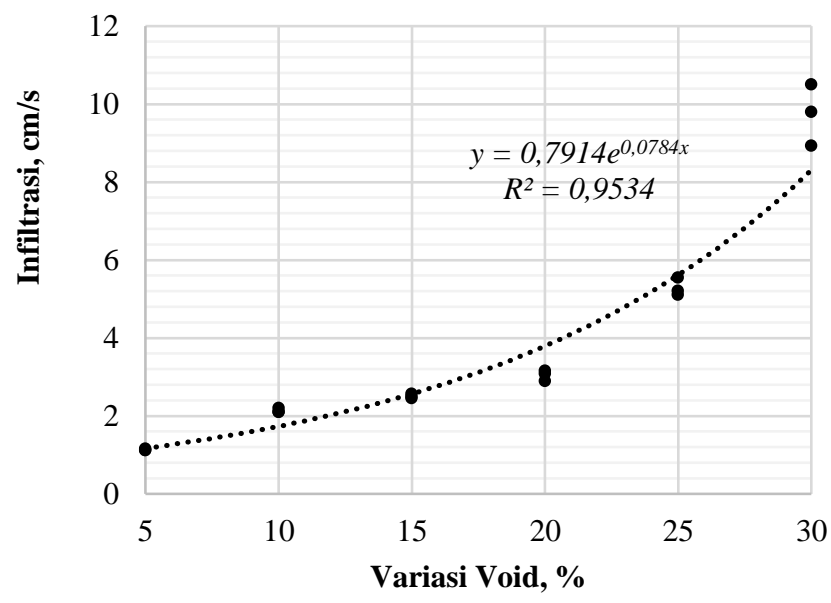

Gambar 5. Hubungan Falling Head dan Void Ratio Sumber: Hasil Analisis

\section{Hasil Pengujian Falling Head}

Sebelum dilakukan pengujian falling head, beton direndam selama 24 jam supaya beton dalam keadaan jenuh air sehingga tidak akan menyerap air pada alat uji ini. Hasil pengujian falling head beton pada Gambar 5 menunjukkan bahwa variasi $5 \%$ ini yang mempunyai nilai falling head terendah pada $1,112 \mathrm{~cm} / \mathrm{s}$ dibanding beton porus lainnya dan nilai tertinggi pada $10,49 \mathrm{~cm} / \mathrm{s}$ yang dihasilkan dari 
pengukuran pada beton dengan void 30\%. Maka hal ini menunjukkan beton berpori dengan void $30 \%$ mempunyai kemampuan inflitrasi paling tinggi. Hasil dari penelitian oleh Qin, dkk [14] menunjukkan angka falling head sebesar 1-4 $\mathrm{cm} / \mathrm{s}$ dengan memvariasi tekanan pada air permukaan beton pori.

\section{Hubungan Kuat Tekan Beton Terhadap Berat Jenis Beton}

Pengujian kuat tekan beton dan berat jenis beton digambarkan dalam grafik dalam Gambar 6 yang menunjukkan meningkatnya berat jenis beton seiring meningkatnya kuat tekan. Hubungan ini dinyatakan dengan fungsi regresi exponential $y=0,0892 e^{0,0025 x}$.

\section{Hubungan Kuat Lentur Beton Dengan Berat Jenis Beton}

Gambar 7 membuktikan bahwa adanya hubungan antara kuat lentur dan berat jenis beton. Pengaruh tersebut terlihat dari semakin besar berat jenis beton maka semakin besar kuat lentur beton dengan fungsi $y=0,0421 e^{0,0018 x}$.

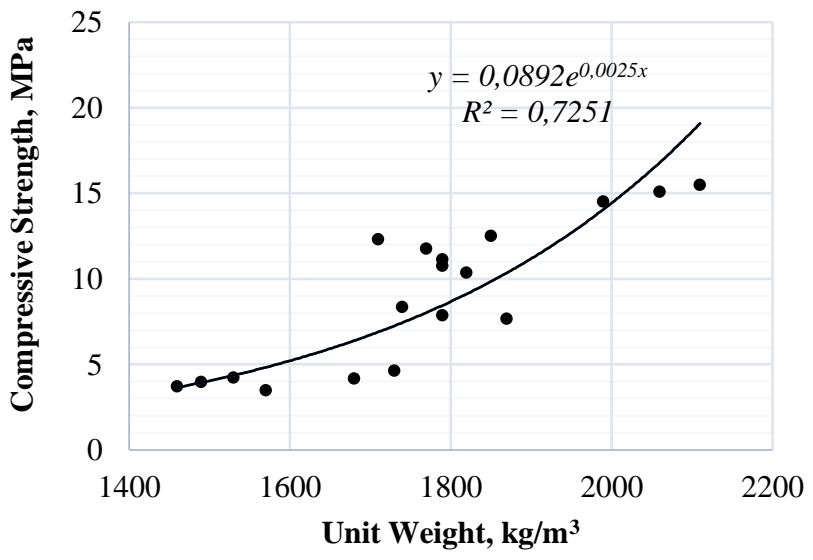

Gambar 6. Hubungan Kuat Tekan dan Berat Jenis Sumber: Hasil Analisis

\section{Waktu getar alami dan kekakuan beton}

Pengujian natural frequency pada beton berpori dilakukan dengan menggunakan satu sampel setiap variasi void, dengan void 5\%,10\%, 15\%, 20\%, 25\%, dan $30 \%$. Setiap sampel diukur menggunakan 2 channel yang diletakan di setengah bentang dan seperempat bentang sehingga memungkinkan didapatkan variasi data yang saling melengkapi. Tabel 2 menunjukkan hasil analisis Fast Fourier Transform berupa natural frequency dan amplitudo dari hasil pengukuran sensor accelerometer

Tabel 2 menunjukkan bahwa waktu getar alami balok cenderung menurun ketika void semakin besar sehingga waktu getar alami balok tertinggi pada balok dengan void $5 \%$ dan terkecil pada void 30\%. Sedangkan kekakuan beton berpori tertinggi terdapat pada beton dengan void 5\% dengan nilai $k=5,8.10^{6}$ dan frekuensi rata-rata $119,141 \mathrm{~Hz}$ serta amplitudo $0,01 \mathrm{~m}$ dan terkecil pada void $30 \%$ dengan kekakuan $3,83.10^{5}$ dan frekuensi $34,18 \mathrm{~Hz}$ serta amplitudo $0,05 \mathrm{~m}$.

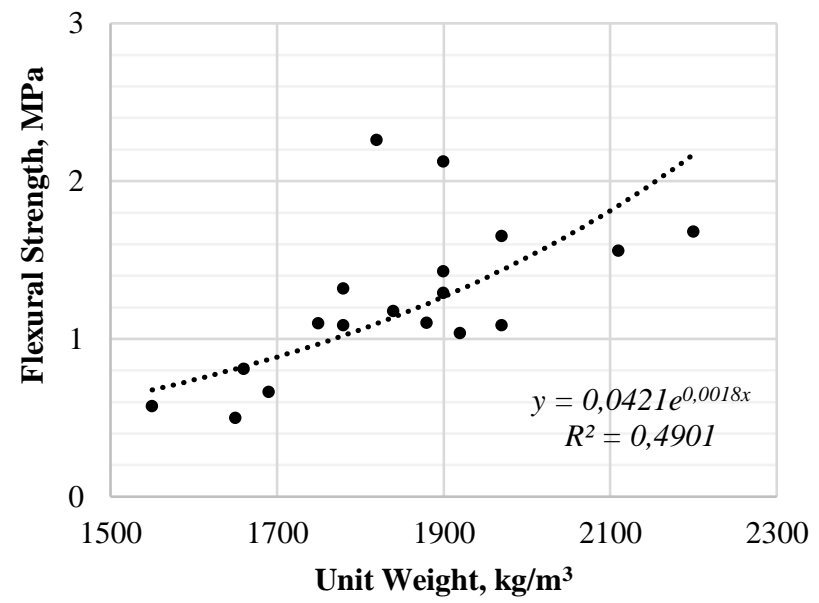

Gambar 7. Hubungan kuat lentur dan berat jenis Sumber: Hasil Analisis

Tabel 2. Natural Frequency Beton Berpori

\begin{tabular}{ccccl}
\hline \multirow{2}{*}{ Void } & $\begin{array}{c}\text { Chan } \\
\text { nel }\end{array}$ & $\begin{array}{c}\text { Natural } \\
\text { Frequency } \\
(\mathbf{H z})\end{array}$ & $\begin{array}{c}\text { Amplitudo } \\
(\mathbf{m})\end{array}$ & $\begin{array}{l}\text { Kekakua } \\
\mathbf{n}\end{array}$ \\
\hline \multirow{2}{*}{$5 \%$} & 0 & 119,141 & 0,01008 & 5808296 \\
& 1 & 119,141 & 0,00970 & 5808296 \\
\hline \multirow{2}{*}{$10 \%$} & 0 & 95,215 & 0,00485 & 3385791 \\
& 1 & 95,215 & 0,00465 & 3385791 \\
\hline \multirow{2}{*}{$15 \%$} & 0 & 64,941 & 0,06144 & 1558734 \\
& 1 & 64,941 & 0,05381 & 1581912 \\
\hline \multirow{2}{*}{$20 \%$} & 0 & 49,805 & 0,04791 & 965900 \\
& 1 & 48,828 & 0,02858 & 910487 \\
\hline \multirow{2}{*}{$30 \%$} & 0 & 50,293 & 0,05896 & 860429 \\
& 1 & 51,758 & 0,03228 & 911281 \\
\hline
\end{tabular}

Sumber: Hasil Analisis dan Pengukuran

\section{Kesimpulan}

Kemampuan beton berpori dengan subsitusi silica fume menunjukkan bahwa semakin besar void maka properti mekanikal akan menurun. Kuat tekan terbesar yaitu 15,45 MPa terjadi pada beton berpori dengan void 5\% dan terkecil 3,45 MPa pada void 30\%. Sedangkan hasil kuat lentur terbesar dicapai beton berpori dengan void $10 \%$ sebesar 2,26 
MPa sedangkan terkecil $0,49 \mathrm{MPa}$ pada void $30 \%$. Kemampuan infiltrasi terbesar dicapai beton berpori $30 \%$ void dengan nilai falling head sebesar $10,49 \mathrm{~cm} / \mathrm{s}$ dan terkecil $1,1 \mathrm{~cm} / \mathrm{s}$ pada void $5 \%$. Kekakuan tertinggi dicapai beton void 5\% dengan nilai $k=5,8.10^{6}$ dan frekuensi rata-rata $119,141 \mathrm{~Hz}$ serta amplitudo $0,01 \mathrm{~m}$ dan terkecil pada void $30 \%$ dengan kekakuan $3,83.10^{5}$ dan frekuensi $34,18 \mathrm{~Hz}$ serta amplitudo $0,05 \mathrm{~m}$.

\section{Daftar Pustaka}

[1] R. Bayuaji, "Studi Kuat Tekan Beton Porus sebagai Material Alternatif Batu Bata dengan Metode Taguchi," Jurnal Aplikasi Teknik Sipil, vol. 11, no. 2, pp. 57-64, 2014.

[2] Hariyadi dan H. Tamai, "Enhancing the performance of porous concrete by utilizing the pumice aggregate," dalam Procedia Engineering 125 ( 2015 ) 732 - 738, The 5th International Conference of Euro Asia Civil Engineering Forum (EACEF-5), Surabaya, 2015.

[3] K. A. Zai, Syahrizal dan R. Karolina, "Pengaruh Penambahan Silica fume dan Superplasticizer terhadap Kuat Tekan Beton Mutu Tinggi dengan Metode ACI (American Concrete Institute)," Jurnal Teknik Sipil USU, vol. 3, no. 2, 2014.

[4] A. M. Rosenberg dan J. M. Gaidis, "A New Mineral Admixture for High-Strength Concrete," Concrete International Design \& Construction Journal, vol. 11, no. 4, Apr. 1989.

[5] S. Garber, R. O. Rasmussen dan D. Harrington, "Guide to Cement Based Integrated Pavement Solutions," Institute for Transportation”, Iowa State University p. 92, Iowa, 2011.

[6] N. Neithalath, J. Weiss dan J. Olek, "Characterizing Enhanced Porosity Using Electrical Impedence to Predict Acoustic and Hydraulic Performance," Cement and Concrete Research Journal, vol. 36, no. 11, pp. 2074-2085, 2006.

[7] J. Yang dan G. Jiang, "Experimental Study on Properties of Pervious Concrete Pavement Materials," Cement and Concrete Research Journal, vol. 33, no. 3, pp. 381-386, 2003.

[8] M. A. Bury, C. A. Mawby dan D. Fisher, "Making Pervious Concrete Placement Easy Using a Novel Admixture System," The RMC Research \& Education Foundation, Concrete Industry Management, Aug, 2013.

[9] M. Kovac dan A. Sicakova, "Pervious Concrete as an Environmental Solution for Pavements: Focus on Key Properties," Environments MDPI Journal, vol. 5, no. 11, pp. 1-9, 2018.

[10] M. I. M. Yusak, R. P. Jaya, M. R. Hainin, C. R. Ismail dan M. H. W. Ibrahim, "Strength of Porous Concrete
Pavement at Different Curing Methods," Jurnal Teknologi UTM, vol. 76, no. 14, p. 99-103, 2015.

[11] D. Dey, "Study on Compressive Strength of Pervious Concrete for Utilisation as Pavement," International Research Journal of Engineering and Technology (IRJET), vol. 4, no. 12, pp. 809-817, 2017.

[12] R. C. Meininger, "No-Fines Pervious Concrete for Paving," Concrete International Journal, vol. 10, no. 8, pp. 20-27, 1988.

[13] M. Kunieda, T. Otono, T. Yoshida, T. Kamada dan K. Rokugo, "Size effect on flexural strength of porous concrete," dalam International Association of Fracture Mechanics for Concrete and Concrete Structures, Vail, 2004.

[14] N. A. Brake, H. Allahdadi dan F. Adam, "Flexural strength and fracture size effects of pervious concrete," Construction and Building Materials Journal, vol. 113, pp. 536-543, 2016.

[15] Y. Qin, H. Yang, Z. Deng dan J. He, "Water Permeability of Pervious Concrete Is Dependent on the Applied Pressure and Testing Methods," Advances in Materials Science and Engineering Journal, vol. 1, no. 6, pp. 1-6, 2015. 